\title{
Research on Intelligent Library Management System
}

\author{
Weihong Yang \\ People's Hospital of Zhengzhou, Zhengzhou 450000, Henan Province, P. R. China \\ tuke126@126.com \\ Corresponding Author: Weihong Yang
}

\begin{abstract}
The concept of control aspects contained the user request permission. In the design application of the Struts framework, the Struts had great advantage as the open source software, which could make the developers at a deeper level of their internal implementation mechanism. In addition, the advantages of Struts also embodied in the Taglib and page navigation. Tablib was the Struts tag library. If it was be flexibled used, it could greatly improve the efficiency of development. The web page navigation system was clearer to read. Through a configuration file, the connection between the various parts of the whole system could be grasped, which helped the system maintenance.
\end{abstract}

Keywords: Intelligent Library Management System.

\section{Introduction of system implementation}

In the implementation part of the system, it mainly adopted the implementation mode of MVC three aspects to realize, in which the V was implemented by the JSP. In order to separated the business logic and expression, it was a web-based application system, with client browser. Then the application of Web aspect, business logic aspect was realized through EJB and resource management. Customer requested to browse pages. Web view was composed by the JSP, and used a log of the Taglib, each request was accordance with certain HTML Action. HTML Action aspect was a standard aspect, performed selected HTML Action. MVC pattern reduced the copy of the code, which reduced the code maintenance. Due to model the return format without any display format, thus model can be directly applied to the usage of the interface.

\section{The Realization of reader management module}

\subsection{Readers' login function implementation}

This feature was mainly that user went into the system through the books management system. User input the correct user name and password, the system will be based on user identity accordingly purview division. There were an error if the login information, then the system prompt error login information, and users of the system for any operation was prohibited. The user login page to write their user names and passwords, select login, the login successful went to the front page of a system, otherwise prompt error message. On the server side of user authentication procedure flow chart was shown in figure 1.

When logged in the system, the first was a user permissions log-in interface. Permissions were mainly to maintain the security and integrity of the system. Operator with administrator was the other operators in the corresponding permissions setting. The operator without permission was not to operate the corresponding window. This system authentication required user firstly apply for user name and password, from software developers was allowed to enter.

\subsection{Readers information management function}

The function of the main was user management system, set up library information such as operation, management system users included to add, modify, delete, and their purview division operation. Main realization of readers' information management, reader management included disposable type management needs, set up different types of readers could use the number of books, 
readers information management was the basic information of the main management maintenance readers.

While setting up information in the system, the management function need input the reader's name, gender, bar code, choose the reader, valid documents, ID number, telephone, E-mail and other information, in which the name, gender, bar code, ID number was mandatory option. In the design, the user permission to the system as an important part of the operation was also the key to improve efficiency system.

\subsection{The realization of the book information management module}

Library information management module mainly included the basic information of the book, category management and intelligent query management books. Intelligent query and the characteristics of this topic research. For the books information and category management here was only to show the effect of its implementation, this section would focus on describe intelligent query function.

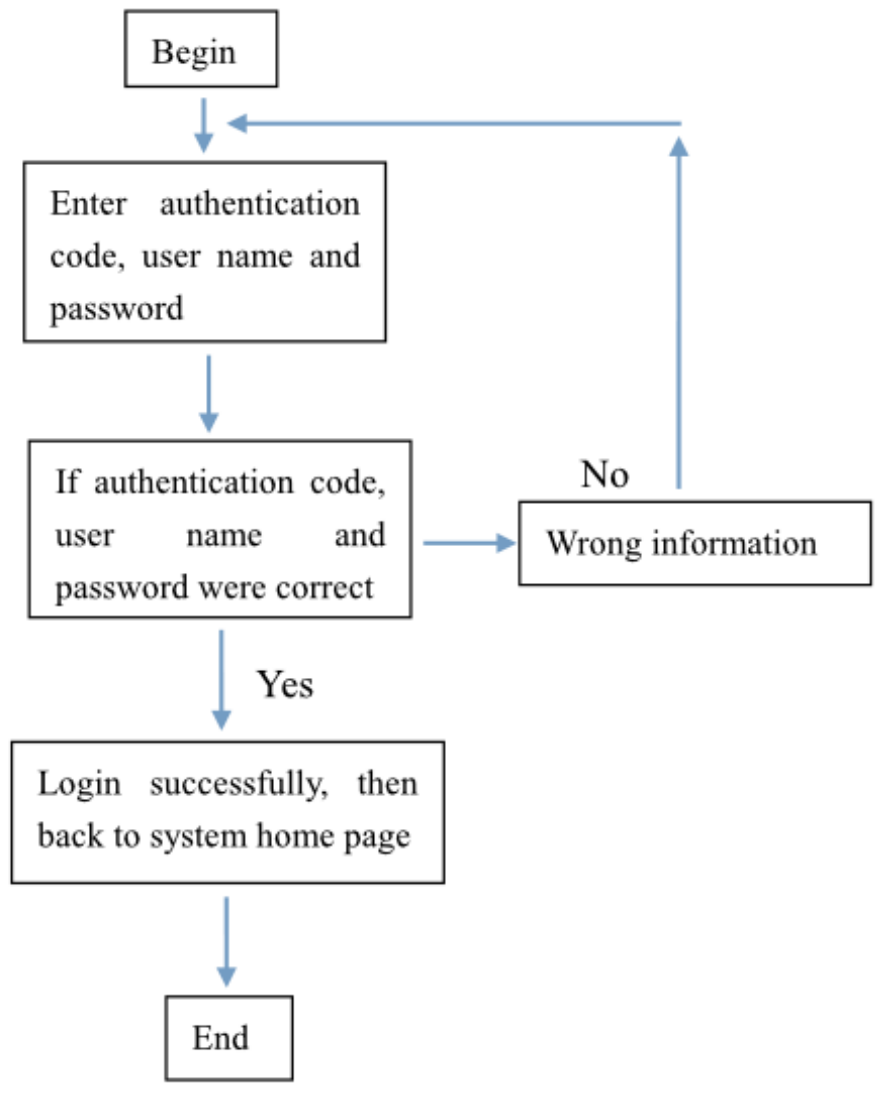

Figure 1. Program flow Chart

\section{Achieved results of basic information and books category management}

Similar to the reader management module, library management module was divided into management and book records management type, including book classification management function. Improve management efficiency, also set up a number of different kinds of books could be borrowed. Management of different types of books. Book records management was to maintain the basic information of the library management.

\subsection{Book information management function implementation effect}

Book basic information contained in the book of the bar code, name of the book, book type, author, translator, prices, press, the shelves of books basic information, including the author, the translator and the page number was optional information. Authentication by later, click could try system the basic information of the management interface, which was a major input information of the administrator. He could input data, which filled in the information, click the save button, system would be to deal with this information. 


\subsection{Books category management to achieve results}

Click could try system the basic information of the management interface, which was a major input information of the administrator. It was the data could be input. It need to fill in the information, click save button, the system would be to deal with the information.

\subsection{The realization of the function intelligent query}

The realization of the Intelligent query functionality was described in the previous chapters which was based on the results of data mining. In this system, mainly provide books information query, library information query two function modules. In book information query, it set up two kinds of query mode, which was a kind of intelligent query mode, the other was a general query mode. Intelligent query mode which was based on data mining query mode, which was according to the result of data mining to display the results of query. Due to the normal mode of common query way, there was not much to deal with, it mainly introduced intelligent query mode.

\subsection{Books intelligent query function}

Unlike ordinary query function, intelligent query function was mainly done on the basic of data mining. Before the query, the reader must log in to the system, the system according to the basic information of the reader and the previous lending management for books, according to users also need to provide the corresponding search criteria.

\subsection{Library information query}

Borrowing query module was on the current state of books and readers lending profile of the current query, with the permissions of the user login and enter the select query condition after the operation interface. And enter the corresponding query information, the system could be in the page shows the query books condition, or the corresponding reader's current lending situation. In addition, one could input the corresponding period of all lending light, or select a query his readers lending conditions with a certain period of time. Inquiry system in the selection date and at the same time constraints, the program was on the basic of query conditions selected in accordance with the contents of the time constraints.

\section{The realization of intelligent library module}

The function of the intelligent library module was to facilitate the reader of the library. Either borrow or return books could be finalized in the module. Its basic principle was the process of operation, as follows: When the readers need to borrow books, just need to click the "library" button on the screen, at the same time, place the unit card on the machine. At this time, some of the basic user information would be displayed on the screen, such as user name, department, etc. Users only needs to input your password set could enter the library management information system. Then place all borrowed books in a particular area, the reader would automatically identify the RFID tags, and then one would get the books bar code. The bar code was one to one correspondence with books. So the system could automatically get the books information, the system would change the state of the library. The last step was to click the button of "be sure of borrowing books". When Readers need to return the books, its process and borrow books, click on the "book" button on the display interface, then put book in the specified area, and then put the unit card in the designated area, the reader, automatic identification RFID tags. Then the RFID tags automatically read the book from the library, through the bar code to return the books information, updated status borrowed at the same time, finally click "confirm" to complete the book, at the same time also can print the certificate of the books.

The above operation were conducted in network without failure, if there have been some unexpected situation, such as network cannot work normally. So at this time, only could also book, borrow books would be banned. It would state first borrowed books in the local database for storage, once the network was normal, were automatically saved to the remote database. 


\section{Conclusion}

Part of this chapter was the realization of the system, the content mainly included, system development situation and technical implementation. One of the specific implementation of all key function modules including: readers information management module, the book information management module and library information management module.

\section{References}

[1] X. Cheng, The application of RFID guide: user-oriented mode, standards, codes and software and hardware[M]. Beijing: Publishing House of Electronics Industry(1st edition),2011.8.

[2] M. Pang, Internet bar code technology and radio frequency identification technology, Beijing: China Fortune Press( 1 st edition),2011,5.

[3] C.L. Zhang, The application of RFID in library management, Electronics World,2013(09):96-97.

[4] H.B. Zhu, L.X. Yang, Q. Zhu, The internet of things technology progress and application, Journal of Nanjing University of Posts and Telecommunication,2011(02):1-9.

[5] J.Y. Li, The internet of things technology application research in the city bus system. Mechanical Engineering \& Automation, 2010(12):211-213.

[6] L.Yu, Y. Lu, X.L. Zhu, The research progress of Internet of things technology. Application Research of Computers, 2012,29(01):1-7.

[7] T.S. Zhu, P.Long, The books management system based on Web design and implementation, Journal of Library and Information Sciences in Agriculture,2009(04):5-6. 